\title{
REVIEW
}

\section{Understanding the Role of Blood Vessels in the Neurologic Manifestations of Coronavirus Disease 2019 (COVID-19)}

\author{
Hannah A.B. Whitmore ${ }^{* \dagger}$ and Leo A. Kim ${ }^{* \dagger}$
}

From the Schepens Eye Research Institute of Massachusetts Eye and Ear, ${ }^{*}$ Boston; and the Department of Ophthalmology, ${ }^{\dagger}$ Harvard Medical School, Boston, Massachusetts

Accepted for publication April 26, 2021.

Address correspondence to Leo A. Kim, M.D., Ph.D., 243 Charles St., Boston, MA 02114. E-mail: leo_kim@meei. harvard.edu.

\begin{abstract}
Severe acute respiratory syndrome coronavirus 2 (SARS-CoV-2) was originally identified as an outbreak in Wuhan, China, toward the end of 2019 and quickly became a global pandemic, with a large death toll. Originally identified as a respiratory disease, similar to previously discovered SARS and Middle East respiratory syndrome (MERS), concern has since been raised about the effects of SARS-CoV-2 infection on the vasculature. This viral-vascular involvement is of particular concern with regards to the small vessels present in the brain, with mounting evidence demonstrating that SARS-CoV-2 is capable of crossing the blood-brain barrier. Severe symptoms, termed coronavirus disease 2019 (COVID-19), often result in neurologic complications, regardless of patient age. These neurologic complications range from mild to severe across all demographics; however, the long-term repercussions of neurologic involvement on patient health are still unknown. (Am J Pathol 2021, 191: 1946-1954; https://doi.org/10.1016/ j.ajpath.2021.04.017)
\end{abstract}

Currently, there are approximately 140 million confirmed infections with severe acute respiratory syndrome coronavirus 2 (SARS-CoV-2) worldwide, and about 3,000,000 deaths associated with SARS-CoV-2 infection (Johns Hopkins University \& Medicine, Coronavirus Resource Center, https://coronavirus.jhu.edu, last accessed April 17, 2021) manifesting as severe coronavirus disease 2019, or coronavirus disease 2019 (COVID-19). Approximately 15\% of individuals affected by COVID-19 develop severe disease, and $6 \%$ are critically ill, resulting in respiratory failure and/or multiple organ dysfunction or failure. ${ }^{1}$ The original outbreak of SARS-CoV-2 infection originated from Wuhan, Hubei province, China, in late 2019., , $^{2}$

Genomic characterization indicates that bats and rodents are the likely gene sources of $\alpha$ - and $\beta$-coronaviruses $(\mathrm{CoVs})$, whereas $\gamma$ - and $\delta$-CoVs likely arise from avian sources. ${ }^{4}$ To date, seven human coronaviruses have been identified with the ability to cause respiratory, enteric, hepatic, and neurologic diseases in different animal species, including cattle and cats. These viruses are responsible for about $5 \%$ to $10 \%$ of acute respiratory infections, including the common cold. ${ }^{4,5}$ SARS-CoV-2 is a member of the $\beta$ coronaviruses and is closely related to severe acute respiratory syndrome coronavirus (SARS-CoV) and Middle East respiratory syndrome coronavirus (MERS-CoV) with high sequence homology. ${ }^{6}$ These coronaviruses appear to infect the respiratory and gastrointestinal tract, with patients presenting symptoms of fever, cough, and shortness of breath, whereas less common symptoms include diarrhea, vomiting, and nausea. ${ }^{7}$ In addition, cytokine release syndrome was found to be the major cause of morbidity in patients infected with SARS-CoV and MERS-CoV. ${ }^{8}$

\footnotetext{
Supported by Michel Plantevin and the National Eye Institute of the NIH award R01EY027739 (L.A.K.).

H.A.B.W. and L.A.K. contributed equally to this work.

Disclosures: L.A.K. is listed as an inventor in a patent application for the treatment of pulmonary fibrosis and coronavirus disease 2019 .

This article is part of a review series on small blood vessel disease in the brain, addressing current knowledge, new mechanisms, biomarkers, and therapeutic approaches.
} 
Aside from the respiratory system, with acute respiratory distress syndrome affecting roughly one-third of COVID-19 hospitalized patients, ${ }^{9}$ COVID-19 appears to also involve multiple organ systems with pathologic manifestations, including the heart, kidney, and brain. ${ }^{10-14}$ Because of the multiorgan involvement of COVID-19, it has been hypothesized that COVID-19 is a vascular disease that primarily affects endothelial cells. ${ }^{15,16}$ These organs, and their associated blood vessels, may be affected by direct viral tissue injury and localized disordered cytokine release. ${ }^{17}$ This direct injury and release of inflammatory and apoptosis inducing mediators leads to localized microvascular inflammation, which triggers endothelial activation, leading to vasodilation and prothrombotic conditions, which cause increased patient mortality. ${ }^{18}$

Viral infections of the brain are less common than those of other organs as they involve penetration of the blood-brain barrier (BBB). Several viruses, including polio and West Nile virus, are able to cause neurologic complications, but the reasons why they occur in $<1$ in 100 patients are not understood. ${ }^{19}$ The route of entry of the virus into the brain, such as in the blood supply, or by direct infection of vascular endothelial cells, plays a role in the number and type of neurologic symptoms presented by the patient. ${ }^{19,20}$ Investigations into MERS-CoV indicated that viral particles enter the bloodstream and are able to infect endothelial cells. ${ }^{21}$ In the case of SARS$\mathrm{CoV}-2$, viral-like particles have been seen in brain capillary endothelium and actively budding across endothelial cells. ${ }^{22}$

Although the route of entry of the virus may still be unknown, recent publications have highlighted neurologic manifestations that have been observed in $42 \%$ of COVID-19 patients at disease onset, 63\% during hospitalization, and $82 \%$ at some time during the course of the disease. ${ }^{23,24}$ In addition, a significant link was seen between magnetic resonance imaging abnormalities and persistent neurologic deficits, which continued 3 months after disease onset in $55 \%$ of patients. ${ }^{23}$

This review explores the role of the vasculature, specifically within the context of the neurologic manifestations of COVID-19. Herein, the neurologic manifestations reported with SARS-CoV-2 infection are reviewed. The evidence that suggests blood vessels are involved in SARS-CoV-2 infection is surveyed. Finally, the multiple pathologic processes (thromboembolic, inflammatory, and secondary processes) within blood vessels that may contribute to the neurologic manifestations of COVID-19 infection are considered.

\section{Composition, Function, and Weaknesses of the Blood-Brain Barrier}

The structure and mode of replication of coronaviruses are related, and the relatedness of human CoVs to the neurotropic animal coronaviruses is predictive of the ability of SARS-CoV-2 to invade the central nervous system (CNS), suggesting some tropism for neural tissue. ${ }^{22,25-29}$ SARS-
CoV-2 has a particularly strong affinity for the angiotensin-converting enzyme 2 (ACE2) receptor, which it attaches to via its spike protein. ${ }^{17,30}$ The ACE2 receptor is ubiquitous across several organ systems, including the lungs, heart, and kidney, but the expression of ACE2 in the brain is significantly lower than that of other organs. ${ }^{30,31}$ However, in an in vitro model of the human BBB, the function of the BBB is negatively affected by the SARSCoV-2 spike protein, and brain endothelial cells showed a distinct proinflammatory response when exposed to the spike protein. ${ }^{32}$ Therefore, the virus must likely overcome the $\mathrm{BBB}$, which plays a critical role in CNS homeostasis, and provides a fundamental level of protection from microorganisms and viruses. ${ }^{33-35}$

The BBB is composed of the endothelial cells that line blood vessels, as well as pericytes, astrocytes, neurons, and the extracellular matrix. ${ }^{35}$ Specifically, the interaction between endothelial cells and pericytes within a common basal lamina via peg-and-socket junctions, as well as the direct encasing of retinal capillaries by astrocytic end feet and microglia, form the neurovascular unit. ${ }^{35}$ Furthermore, the endothelial cells in particular, within the CNS, form a tight barrier via continuous tight junctions, lack of fenestration, and low pinocytic activity, drastically limiting the transport of molecules between the vascular system and the CNS. ${ }^{34}$

Despite this barrier, the CNS can be reached by some viruses that can infect neurons and glial cells. ${ }^{28}$ Although experimental evidence regarding SARS-CoV-2 neuroinvasiveness is still lacking, there is evidence obtained through post-mortem studies that indicate that the virus has reached the brain microvasculature, cerebrospinal fluid (CSF), as well as the neurons. ${ }^{36}$ This may in part be due to the fact that not all blood vessels within the CNS are composed of the cellular constituents of the neurovascular unit, and the integrity of the BBB varies throughout some portions of the CNS, such as the choroid plexus or the circumventricular organs, allowing for secretion of CSF and other neurosecretory functions. ${ }^{20,37}$ Thus, there is heterogeneity within CNS regions with respect to the barrier function of the BBB. ${ }^{38}$

Because of the similarities between coronaviruses, it is highly likely that SARS-CoV-2 is neuroinvasive and neurotropic, just like SARS-CoV. ${ }^{28}$ Neuronal retrograde dissemination as well as hematogenous dissemination are potential pathways for SARS-CoV-2 to enter the CNS. Neuronal retrograde dissemination uses a protein called dynein to move viruses along the axon in the retrograde direction, from synapse to soma. ${ }^{39}$ This is known to occur in viral infections, such as HIV, where it contributes to viral latency. ${ }^{29}$ The proposed route of retrograde viral transport originates at the nasal cavity, the site of the mild SARSCoV-2 neurologic symptom anosmia, ${ }^{40}$ and ends at the brainstem, as follows: nasal cavity $>$ olfactory nerve $>$ olfactory bulb $>$ piriform cortex $>$ brainstem. ${ }^{30,41}$ Another proposed route of infection involves endothelial cells and leukocyte trafficking. While in a healthy state, the 
CNS is devoid of leukocytes, ${ }^{42}$ in an inflammatory setting, such as a viral infection, the infection can be established in the CNS by taking advantage of leukocyte trafficking. ${ }^{43}$ This process may involve direct infection of cerebral vascular endothelial cells due to leukocyte tethering, which allows immediate passage across the $\mathrm{BBB}$ into the CNS. ${ }^{20,44}$ In addition to leukocyte activation and the trafficking of infected leukocytes through the blood-brain, the blood-CSF barrier may also be utilized as a hematogenous dissemination route, whereby infected hematopoietic cells are used as Trojan horses to transport virus into the CNS via the blood supply. ${ }^{20,28,43}$ A systemic viral infection can also lead to inflammation-induced breakdown of the BBB, allowing viruses to slip through literal cracks between endothelial cells and into the CNS. ${ }^{20,28,43}$

Although the activation, inflammation, and immune response of endothelial cells may be enough to compromise the $\mathrm{BBB}$ alone, the actions of the matrix metalloproteinase family of proteins may play a role in BBB integrity loss. Matrix metalloproteinase proteins are specifically relevant to BBB integrity, and up-regulation of SARS-CoV-2 spike protein has been shown to significantly up-regulate many of these key proteins. ${ }^{32}$ This highly specific, localized proinflammatory response may offer a route for SARS-CoV-2 to breach the BBB. ${ }^{32}$ The heterogeneity of barrier function within the CNS may additionally explain some of the variability of neurologic manifestations of COVID-19.

\section{Neurologic Manifestations of SARS-CoV-2 Infection}

Patients with severe respiratory disease are reported to have multiple neurologic manifestations. In a case study of 509 consecutive patients admitted with confirmed COVID-19 in Chicago, IL, a significantly higher risk of neurologic complications was seen in patients with severe symptoms of COVID-19. ${ }^{23}$ Many of the coronaviruses discovered to date have similar structures and infection mechanisms as well as similar neuro-invasive potential. ${ }^{28,45}$ The neuroinvasiveness of SARS-CoV has been established previously, and because of the similarities between the two coronaviruses, a similar risk of neuro-invasiveness may be extrapolated to SARS-CoV-2. ${ }^{22,25-30,36,45}$

The coronavirus family, including SARS-CoV-2, has been associated with seizures, status epilepticus, encephalitis, acute disseminated encephalomyelitis, Guillan-Barre syndrome, leukoencephalopathy, and critical illness neuromyopathy. ${ }^{46,47}$ More recently (in 2003), SARS-CoV was detected in the cerebrospinal fluid of a patient with SARS. ${ }^{48,49}$ Although coronaviruses, including SARS-CoV2 , have been isolated from brain tissue in autopsy specimens, the presence of neutralizing antibodies in patient serum and cerebrospinal fluid has also been detected. $22,33,50$
Multiple neurologic manifestations, varying from nonspecific to specific symptoms, have been reported with SARS-CoV-2 infection. ${ }^{51}$ Mild neurologic symptoms include headache, dizziness, hypogeusia, hyposmia, and neuralgia. ${ }^{52,53}$ The underlying mechanisms of these neurologic effects are likely numerous, including direct viral transmission through the olfactory nerve,$^{40}$ hypoxic brain injury, or immune mediated, via disruption of the bloodbrain barrier. ${ }^{32}$

The likely early symptoms of COVID-19 include a fever and headache, with approximately $11 \%$ of emergency departments presenting patients experiencing headache. ${ }^{51}$ As headaches are a common neurologic response to many daily concerns, including stress, tension, and dehydration, ${ }^{54}$ the presentation of this symptom is widely variable and cannot be considered in isolation, although poor response to common analgesics is common. ${ }^{53}$ Patients have reported headaches as pulsating, stabbing, or pressing, which normally indicates different headache types, such as migraine or tension. In the context of COVID-19, headache is likely to occur in conjunction with gastrointestinal symptoms. ${ }^{53}$ These dual symptoms of gastrointestinal tract involvement with headache are linked to the gut-brain axis, which is affected by significant cytokine release, common in COVID-19 patients, ${ }^{17,18,55}$ including tumor necrosis factor$\alpha$, ILs, and calcitonin gene-related peptide, a neuropeptide significantly linked to trigeminovascular activation, which leads to headache. ${ }^{53}$

Further neurologic complications and cerebrovascular events include cerebrovascular accident, Guillian-Barre syndrome, acute transverse myelitis, and, although difficult to detect, acute encephalitis. ${ }^{14,46}$ Encephalitis, or inflammation of the brain, is known to occur after some viral infections, including varicella zoster and influenza A viruses. ${ }^{56}$ Coronaviruses have been detected in both the cerebrum and cerebrospinal fluid of individuals with seizures, encephalitis, and encephalomyelitis. The first case of encephalitis associated with SARS-CoV-2 infection was reported in May 2020 in a 24-year-old man, ${ }^{57}$ and since then, many more cases have been identified. ${ }^{58}$ The higher risk of neurologic complications in patients with severe symptoms is caused primarily by a higher frequency of encephalopathy, especially in older patients. ${ }^{14,23}$ Patients diagnosed with encephalitis have demonstrated signs of immune-mediated small-vessel damage, leading to altered integrity of the blood-brain barrier and brain edema. ${ }^{59}$

Secondary CNS vasculitis is a rare condition characterized by inflammation of the blood vessels in the brain or spine caused by viral infection, leading to varied symptoms, including confusion and significant forgetfulness ${ }^{60}$ Because of its rarity, few patients diagnosed with COVID-19 have exhibited symptoms and been included in case studies as confirmed vasculitis patients. The condition often presents as multiple ischemic small-vessel lesions and hyperdense blood areas, with scans showing injury to the intracranial microvasculature. ${ }^{27,60}$ The pattern seen on the scans is 
characteristic of disease processes that progress from endoluminal, vessel wall (vasculitis), or perivascular (leukoencephalopathy) cellular proliferation. ${ }^{27}$ Of the few case studies available, patients were treated with steroids and immunoglobulin (Ig), as well as IL inhibitors, with varied outcomes for the patients. ${ }^{26,60,61}$

An increased rate of ischemic stroke and intracerebral hemorrhage has been reported among COVID-19 patients. $^{62,63}$ Cerebrovascular accident (alias stroke) is associated with COVID-19 diagnosis, across all age ranges, but is especially concerning in younger patients (aged $<50$ years) without the expected risk factors. ${ }^{12}$ Viral infections cause strokes by increasing the risks for embolism. ${ }^{13,64}$ Hypercoagulopathy, resulting from viral effects on systemic and CNS coagulation pathways, has been a growing concern, and anticoagulant administration is associated with decreased mortality in COVID-19 patients. In a case study of 32 critically ill patients, 8 had severe CNS involvement. Three patients were imaged with vessel wall sequence magnetic resonance imaging and showed contrast enhancement, suggesting large-vessel pathologies with an inflammatory component; however CSF samples were negative for SARS-CoV-2. ${ }^{11}$ There have since been reports that PCR analysis of the CSF may be not reliable for the diagnosis because SARS-CoV-2 dissemination in the brain can be transient and its CSF titer may be extremely low. ${ }^{65}$ Across the published articles available by mid-2020, it was calculated that between $0.2 \%$ and $1 \%$ of those infected with COVID-19 develop ischemic strokes. ${ }^{11}$ This compares with annual rates of roughly $0.1 \%$ of the population in the United Kingdom and $0.2 \%$ of the population in the United States. Both the presentation and outcome are generally worse in stroke associated with a COVID-19 diagnosis compared with other strokes. ${ }^{12}$ Patients whose symptoms include severe pneumonia and multiorgan failure are more likely to additionally develop stroke, and the outcome for these patients is poor. ${ }^{66,67}$ Reported cerebrovascular events are predominantly found in older patients; however, acute mental state alterations, although represented in all age groups, are considered to be disproportionately found in younger patients. ${ }^{24,68}$

Additional, long-term studies are required, but there is also speculation that COVID-19 infection may have longterm negative implications on the incidence of Alzheimer disease within the population. ${ }^{69}$ Disrupted cardiorespiratory function causes metabolic dysfunction that may increase risk for future Alzheimer disease and related dementia, whereas the extreme inflammatory response to the infection causes the release of ILs and tumor necrosis factor- $\alpha{ }^{70}$ Proinflammatory cytokine expression promotes oxidative stress, which, if unchecked, degrades mitochondria, causes DNA mutations, and accelerates apoptosis. ${ }^{71}$ This cell death may lead to neural dysfunction and an acceleration in neural decline over time. ${ }^{70}$

These data on the impact of the CNS insult to patients support the fact that the neurologic complications from
SARS-CoV-2 infection may have longer-lasting consequences, and in fact be more debilitating, than the initial respiratory symptoms of the disease. ${ }^{26}$

\section{Blood Vessels in SARS-CoV-2 Infection}

As COVID-19 mainly presents as a respiratory disease, it is not surprising that post-mortem studies in patients with COVID-19 identified diffuse alveolar damage in patients with severe disease, indicating pulmonary epithelial cell involvement. ${ }^{72}$ However, several studies also describe severe endothelial damage and coagulopathic features in the pulmonary microvasculature (Figure 1). ${ }^{18,72}$ Human brain microvascular endothelial cells are known to be infected by several virus types, including HIV, polio, and SARS-CoV$2{ }^{62,73-75}$ Viral migration into the brain occurs in several ways, including tight junction modulation, ${ }^{73}$ receptor activation, ${ }^{75}$ hematogenous dissemination, ${ }^{28,34}$ and direct endothelial cell infection. ${ }^{74}$ Like many other viruses, the mechanisms underlying cerebral endothelial susceptibility and individual patient neurologic responses to SARS-CoV-2 are unknown. ${ }^{19,62}$

Endothelial cells in a healthy environment are able to prevent coagulation, inhibit inflammation, and control blood flow and the passage of proteins from blood into tissues by modulation of vascular permeability. ${ }^{76,77}$ Evidence based on COVID-19 risk factors, which include old age, obesity, hypertension, and diabetes mellitus, indicates a link between endothelial cells and COVID-19, as all of the above are characterized by pre-existing vascular dysfunction. ${ }^{77}$ As endothelial cells play a crucial role in maintaining hemostasis and vessel wall integrity, localized dysfunction of pulmonary microvascular cells is likely to be a key component in the thromboinflammatory processes that result in COVID-19 vasculopathy. ${ }^{78}$

Evidence from autopsies indicates direct viral tissue injury and localized cytokine release induce microvascular inflammation, which triggers endothelial activation. ${ }^{18}$ This is seen in several organs, including the lungs ${ }^{79}$ and kidneys. ${ }^{10}$ The lungs of COVID-19 autopsy patients have features of severe endothelial injury associated with intracellular SARS-CoV-2 virus and disrupted endothelial cell membranes. ${ }^{72,79}$ The lungs have also been found to contain widespread vascular thrombosis with microangiopathy and occlusion of alveolar capillaries, ${ }^{72}$ whereas the kidneys show evidence of vasodilation and prothrombotic conditions, ${ }^{18}$ as well as cell swelling and capillary occlusion. ${ }^{10}$

There is also significant evidence of heart damage, seen in upwards of one-third of hospitalized COVID-19 patients. $^{80}$ Comorbidities of severe COVID-19, which are linked to vascular endothelial damage, such as atherosclerosis, cause significant damage to the endothelial glycocalyx, whereas SARS-CoV-2 can induce cytokine release, also leading to systemic degradation of the vascular endothelial glycocalyx. ${ }^{81}$ This causes microvascular leakage and initiates 


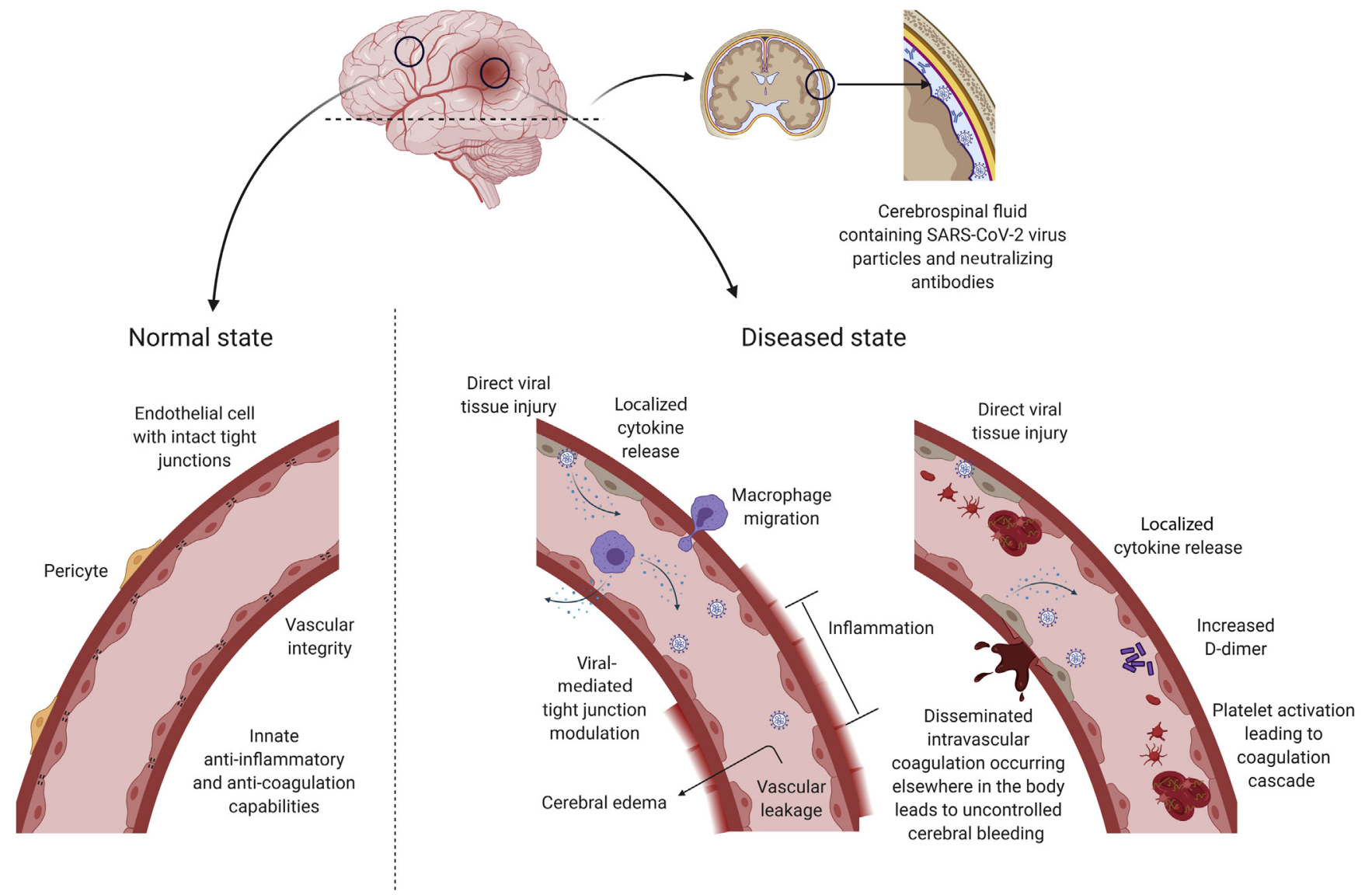

Figure 1 Comparison of normal blood vessels versus potential disease states of blood vessels in severe acute respiratory syndrome coronavirus 2 (SARS-CoV-2) patients. The figure was generated with Biorender.com (BioRender, Toronto, ON, Canada).

changes in the coagulation cascade. ${ }^{81,82}$ Microthrombosis of the small-vessel myocardial vasculature is a relatively common finding in COVID-19 patients and may persist even after viral clearance. ${ }^{80}$

Further evidence of vascular cell involvement in coagulopathy, most obviously seen in thrombi formation in the lungs and in ischemic strokes, is also visible in the blood vessels of the skin. Rashes, described as livedoid and purpuric, are visible manifestations of a suspected underlying pulmonary thrombotic state in COVID-19 patients. ${ }^{83}$ These rashes have been noted to occur in patients already receiving therapeutic dose anticoagulation therapies to stave off suspected pulmonary embolism. ${ }^{83}$ These symptoms are associated with occlusive vascular disease, ${ }^{84}$ especially as punch biopsies indicated pauci-inflammatory thrombogenic vasculopathy involving capillaries, venules, and/or arterioles in conjunction with significantly elevated D-dimer levels. In these cases, patients were not believed to be experiencing alternate conditions resulting in thrombi formation, including disseminated intravascular coagulation (DIC), because of their normal levels of fibrinogen. ${ }^{83}$

Disruption of the endothelial cells is not an end point in itself, but rather a component of a thromboinflammatory feedback loop within small vessels, wherein disruption, cytokine release, and coagulation cascade activation lead to a comparably hypoxic environment that exacerbates the aforementioned factors. ${ }^{78}$ Although, in the lungs, thrombotic complications are likely to relate, at least in part, to endothelial inflammation and injury, its in the cerebrovascular system is currently limited. ${ }^{61}$

\section{Mechanisms of Vascular Damage in SARS-CoV-2 Infection}

Cytokine release syndrome, also described as cytokine storm, is of serious concern in COVID-19 patients as it has been linked to increased patient mortality. ${ }^{8,17,18,55}$ Viral infection leads to the release of antiviral cytokines, such as interferon- $\alpha \beta{ }^{8}{ }^{8}$ This leads to the release of proinflammatory cytokines, such as tumor necrosis factor- $\alpha$ and IL- 6 and IL$1 \beta$, as well as chemokines, including vascular endothelial growth factor, monocyte chemoattractant protein-1, and CXCL10. ${ }^{8,17,55}$ Although the relative levels of these cytokines are well below those found in acute respiratory distress syndrome patients, ${ }^{18}$ they are far above normal and their presence in COVID-19 patients is now being used as biomarkers and predictors of future care. ${ }^{23,85}$ For example, IL-6 expression is significantly higher in fatal outcomes 
compared with survivors and is also used an indicator of the need for mechanical ventilation. ${ }^{85}$

The activated phenotype of endothelial cells, which is induced by inflammatory cytokines and chemokines, promotes adhesions and infiltration of neutrophils, which produce large amounts of histotoxic mediators, including neutrophil extracellular traps, which leads to endothelial cell injury. ${ }^{77}$ These activated endothelial cells initiate coagulation by expressing fibrinogen, among others, leading to platelet binding, fibrin production, and thrombus formation. ${ }^{86}$ The microvascular inflammation caused by release of inflammatory and apoptosis-inducing mediators, followed by endothelial activation, leads to increased patient mortality. ${ }^{18}$

The main SARS-CoV-2 cellular receptor, ACE2, has regional variability within the human brain but is poorly expressed by human brain endothelial cells. ${ }^{23,62} \mathrm{Up}$ regulation of ACE2 in the brain is linked to oxidative stress, apoptosis, and neurodegeneration. ${ }^{23}$ ACE2 expression can be triggered in vitro in a flow-dependent manner, which indicates that cerebral vessels are susceptible to SARS-CoV-2 infection. ${ }^{62}$ However, the question remains as to whether the pathobiology and neuroinfectiveness of SARS-CoV-2 mean that damage occurs from direct effects of the virus on the CNS tissue, or whether damage occurs as a secondary insult, triggered by hypoxia, immune response cytokine release, or clotting cascades. ${ }^{23}$

Within the CNS, one proposed route of infection is direct infection of cerebral vascular endothelial cells due to leukocyte tethering and trafficking, ${ }^{43}$ which allows immediate passage across the BBB into the CNS. ${ }^{20,44}$ Autopsied patients have SARS-CoV-2-infected frontal lobe microvascular endothelial cells and tissue damage, characterized by cell lysis and dysfunction, as well as evidence of localized cytokine release, ${ }^{18,77}$ a probable cause of the prevalence of vessel inflammation seen in scans. ${ }^{11}$ Interestingly, although ACE2 receptor is required for SARS-CoV-2 to bind and gain access to the cell, this binding reduces ACE2 enzyme activity, activating the kallikrein-bradykinin pathway, and increasing vascular permeability. ${ }^{77}$ This increased permeability leads to the release of inflammatory cytokines such as ILs and tumor necrosis factor- $\alpha$, whose downstream mediators promote fluid retention, leading to increased vascular leakage. ${ }^{76,77}$ Likely cofactors remain a mystery, however, in our understanding of the association of SARS-CoV-2 infection with cerebrovascular events.

Although considered a mild symptom, headache caused by SARS-CoV-2 infection is attributed to a possible pathophysiological mechanism involving the peripheral trigeminal nerve endings. This occurs either by direct viral activation or through vasculopathy caused by increased circulating proinflammatory cytokines and hypoxia. ${ }^{53,54}$ With regard to the rare neurologic symptoms, including encephalitis and vasculitis, immunemediated small-vessel damage, leading to altered integrity of the blood-brain barrier, followed by brain edema, is the proposed mechanism. ${ }^{59}$ In patients with vasculitis, this immunemediated small-vessel damage leads to ischemic lesions, as well as hyperdense blood areas, due to intracranial microvasculature injury. ${ }^{27,60}$ Immune-related COVID-19 pathology in pediatric populations was recently described in the United States and in Europe. These children developed a Kawasakilike syndrome, believed to be associated with COVID-19. ${ }^{87}$ Kawasaki disease is characterized by a high fever and systemic vasculitis and may result in neurologic complications. ${ }^{30}$

In patients diagnosed with COVID-19, both ischemic and hemorrhagic strokes are possible, although hemorrhagic strokes are less likely. ${ }^{66,88}$ The rate of patients experiencing ischemic stroke is significantly elevated over the normal population. ${ }^{46}$ Hypotheses as to the mechanism of action for both ischemic and hemorrhagic stroke onset include disseminated intravascular coagulation (alias consumption coagulopathy $^{89}$ as well as significantly increased levels of D-dimer. ${ }^{2,18}$ Rates of COVID-19 complicated by disseminated intravascular coagulation have been reported as $0.6 \%$ for survivors and $71.4 \%$ for nonsurvivors. ${ }^{89}$ Although most patients experience ischemic stroke, some patients experience secondary hemorrhagic transformations of ischemic strokes. ${ }^{88,90,91}$ This transition is indicative of serious malfunctions in both the clotting cascade, possibly due to disseminated intravascular coagulation, as well as lack of integrity of the vessel walls caused by endothelial damage. ${ }^{88,91}$ This immune-driven endothelial damage is likely a large contributor to the increased risk of ischemic and hemorrhagic stroke seen in COVID-19 patients. ${ }^{66}$ In addition, hypercoagulability and vasculitis due to intracranial cytokine storm, leading to macrothrombi and microthrombi formation in the vessels, are also proposed as mechanisms. ${ }^{11,13,92}$

\section{Conclusion}

The large number of studies relating to COVID-19 (an early January 2021 PubMed search returned >85,000 COVID-19 hits) indicate the urgency in the scientific community to determine the factors causing increased patient mortality. Although improving patient survival rates is of the utmost importance, the impact of the endothelium-linked CNS insult to COVID-19 patients cannot be overstated. Research articles discussing long COVID and post-COVID-19 neurological syndrome have been recently published..$^{93,94}$ As the pandemic is still ongoing, it is too early to describe the future clinical needs of these patients. However, current evidence indicates that the long-term neurologic complications from SARS-CoV-2 infection may be more debilitating than the initial respiratory symptoms of the disease. ${ }^{26,69,70,93}$

\section{Acknowledgments}

We thank Michel Plantevin and Andrew Firger for supporting publication. H.A.B.W. thanks the Consular Information Unit and the Nonimmigrant Visa Unit at the US Embassy in London, UK, for assistance in obtaining a National Interest Exemption Waiver to allow her return to the United States 
during the COVID-19 pandemic to work on this project. L.A.K. thanks Dr. Nahyoung Grace Lee for support.

\section{References}

1. Wu Z, McGoogan JM: Characteristics of and important lessons from the coronavirus disease 2019 (COVID-19) outbreak in China: summary of a report of 72314 cases from the Chinese Center for Disease Control and Prevention. JAMA 2020, 323:1239-1242

2. Leisman DE, Deutschman CS, Legrand M: Facing COVID-19 in the ICU: vascular dysfunction, thrombosis, and dysregulated inflammation. Intensive Care Med 2020, 46:1105-1108

3. Huang C, Wang Y, Li X, Ren L, Zhao J, Hu Y, Zhang L, Fan G, Xu J, Gu X, Cheng Z, Yu T, Xia J, Wei Y, Wu W, Xie X, Yin W, Li H, Liu M, Xiao Y, Gao H, Guo L, Xie J, Wang G, Jiang R, Gao Z, Jin Q, Wang J, Cao B: Clinical features of patients infected with 2019 novel coronavirus in Wuhan, China. Lancet 2020, 395:30183-30185

4. Al-Sharif E, Strianese D, AlMadhi NH, D'Aponte A, dell'Omo R, DiBenedetto R, Costagliola C: Ocular tropism of coronavirus (CoVs): a comparison of the interaction between the animal-to-human transmitted coronaviruses (SARS-CoV-1, SARS-CoV-2, MERS-CoV, CoV-229E, NL63, OC43, HKU1) and the eye. Int Ophthalmol 2021, 41:349-362

5. Yin Y, Wunderink RG: MERS, SARS and other coronaviruses as causes of pneumonia. Respirology 2018, 23:130-137

6. Wu A, Peng Y, Huang B, Ding X, Wang X, Niu P, Meng J, Zhu Z, Zhang Z, Wang J, Sheng J, Quan L, Xia Z, Tan W, Cheng G, Jiang T: Genome composition and divergence of the novel coronavirus (2019$\mathrm{nCoV}$ ) originating in China. Cell Host Microbe 2020, 27:325-328

7. De Wit E, Van Doremalen N, Falzarano D, Munster VJ: SARS and MERS: recent insights into emerging coronaviruses. Nat Rev Microbiol 2016, 14:523-534

8. Channappanavar R, Perlman S: Pathogenic human coronavirus infections: causes and consequences of cytokine storm and immunopathology. Semin Immunopathol 2017, 39:529-539

9. Tzotzos SJ, Fischer B, Fischer H, Zeitlinger M: Incidence of ARDS and outcomes in hospitalized patients with COVID-19: a global literature survey. Crit Care 2020, 24:516

10. Su H, Yang M, Wan C, Yi L-X, Tang F, Zhu H-Y, Yi F, Yang H-C, Fogo AB, Nie X, Zhang C: Renal histopathological analysis of 26 postmortem findings of patients with COVID-19 in China - Kidney International. Kidney Int 2020, 98:219-227

11. Keller E, Brandi G, Winklhofer S, Imbach LL, Kirschenbaum D, Frontzek K, Steiger P, Dietler S, Haeberlin M, Willms J, Porta F, Waeckerlin A, Huber M, Abela IA, Lutterotti A, Stippich C, Globas C, Varga Z, Jelcic I: Large and small cerebral vessel involvement in severe COVID-19. Stroke 2020, 51:3719-3722

12. Altable M, De La Serna JM: Cerebrovascular disease in COVID-19: is there a higher risk of stroke? Brain Behav Immun Health 2020, 6: 100092

13. Avula A, Nalleballe K, Narula N, Sapozhnikov S, Dandu V, Toom S, Glaser A, Elsayegh D: COVID-19 presenting as stroke. Brain Behav Immun 2020, 87:115-119

14. Haider A, Siddiqa A, Ali N, Dhallu M: COVID-19 and the brain: acute encephalitis as a clinical manifestation. Cureus 2020, 12:e10784

15. Libby P, Lüscher T: COVID-19 is, in the end, an endothelial disease. Eur Heart J 2020, 41:3038-3044

16. Siddiqi HK, Libby P, Ridker PM: COVID-19 - a vascular disease. Trends Cardiovasc Med 2021, 31:1-5

17. Moore JB, June CH: Cytokine release syndrome in severe COVID19. Science 2020, 368:473-474

18. Leisman DE, Ronner L, Pinotti R, Taylor MD, Sinha P, Calfee CS, Hirayama AV, Mastroiani F, Turtle CJ, OHarhay M, Legrand M, Deutschmann CS: Cytokine elevation in severe and critical COVID-19: a rapid systematic review, meta-analysis, and comparison with other inflammatory syndromes. Lancet Respir Med 2020, 8:1233-1244
19. van den Pol AN: Viral infection leading to brain dysfunction: more prevalent than appreciated? Neuron 2009, 64:17-20

20. Swanson PAI, McGavern DB: Viral diseases of the central nervous system. Curr Opin Virol 2015, 11:44-54

21. Hocke AC, Becher A, Knepper J, Peter A, Holland G, Tönnies M, Bauer TT, Schneider P, Neudecker J, Muth D, Wendtner CM, Rückert JC, Drosten C, Gruber AD, Laue M, Suttorp N, Hippenstiel S, Wolff T: Emerging human Middle East respiratory syndrome coronavirus causes widespread infection and alveolar damage in human lungs. Am J Respir Crit Care Med 2013, 188:882-886

22. Paniz-Mondolfi A, Bryce C, Grimes Z, Gordon RE, Reidy J, Lednicky J, Sordillo EM, Fowkes M: Central nervous system involvement by severe acute respiratory syndrome coronavirus-2 (SARS-CoV-2). J Med Virol 2020, 92:699-702

23. DeKosky ST, Kochanek PM, Valadka AB, Clark R, Chou SH, Au AK, Horvat C, Jha RM, Mannix R, Wisniewski SR, Wintermark M, Rowell SE, Welch RD, Lewis L, House S, Tanzi RE, Smith DR, Vittor AY, Denslow ND, Davis MD, Glushakova OY, Hayes RL: Blood biomarkers for detection of brain injury in COVID19 patients. J Neurotrauma 2020, 38:1-43

24. Liotta EM, Batra A, Clark JR, Shlobin NA, Hoffman SC, Orban ZS, Koranic IJ: Frequent neurologic manifestations and encephalopathyassociated morbidity in Covid-19 patients. Ann Clin Transl Neurol 2020, 7:2221-2230

25. Reddy ST, Garg T, Shah C, Nascimento FA, Imran R, Kan P, Bowry R, Gonzales N, Barreto A, Kumar A, Volpi J, Misra V, Chiu D, Gadhia R, Savitz SI: Cerebrovascular disease in patients with COVID-19: a review of the literature and case series. Case Rep Neurol 2020, 12:199-209

26. Ghoush MSA, ElBashari M, Alzaabi A, Aboelnaga M: COVID-19 vasculitis: a case report with complicated course. Am J Med Case Rep 2020, 8:428-430

27. Hanafi R, Roger P-A, Perin B, Kuchcinski G, Deleval N, Dallery F, Michel D, Hacein-Bey L, Pruvo J-P, Outteryck O, Constans J-M: COVID-19 neurologic complication with CNS vasculitis-like pattern. Am J Neuroradiol 2020, 41:1384-1387

28. Desforges M, Le Coupanec A, Brison E, Meessen-Pinard M, Talbot PJ: Neuroinvasive and neurotropic human respiratory coronaviruses: potential neurovirulent agents in humans. Adv Exp Med Biol 2014, 807:75-96

29. Antinone SE, Smith GA: Retrograde axon transport of herpes simplex virus and Pseudorabies virus: a live-cell comparative analysis. J Virol 2010, 84:1504-1512

30. Bougakov D, Podell K, Goldberg E: Multiple neuroinvasive pathways in COVID-19. Mol Neurobiol 2021, 58:564-575

31. Lukiw WJ, Pogue A, Hill JM: SARS-CoV-2 infectivity and neurological targets in the brain. Cell Mol Neurobiol 2020, [Epub ahead of print] doi:10.1007/s10571-020-00947-7

32. Buzhdygan TP, DeOre BJ, Baldwin-Leclair A, Bullock TA, McGary HA, Khan JA, Razmpour R, Hale JF, Galie PA, Potula R, Andrews AM, Ramirez SH: The SARS-CoV-2 spike protein alters barrier function in 2D static and 3D microfluidic in-vitro models of the human blood-brain barrier. Neurobiol Dis 2020, 146:105131

33. Alexopoulos H, Magira E, Bitzogli K, Kafasi N, Vlachoyiannopoulos P, Tzioufas A, Kotanidou A, Dalakas MC: Anti-SARS-CoV-2 antibodies in the CSF, blood-brain barrier dysfunction, and neurological outcome: studies in 8 stuporous and comatose patients. Neurol Neuroimmunol Neuroinflam 2020, 7:e893

34. Engelhardt B, Liebner S: Novel insights into the development and maintenance of the blood-brain barrier. Cell Tissue Res 2014, 355: 687-699

35. Liebner S, Dijkhuizen RM, Reiss Y, Plate KH, Agalliu D, Constantin G: Functional morphology of the blood-brain barrier in health and disease. Acta Neuropathol 2018, 135:311-336

36. Baig AM, Sanders EC: Potential neuroinvasive pathways of SARS-CoV2: deciphering the spectrum of neurological deficit seen in coronavirus disease-2019 (COVID-19). J Med Virol 2020, 92:1845-1857 
37. Sisó S, Jeffrey M, González L: Sensory circumventricular organs in health and disease. Acta Neuropathol 2010, 120:689-705

38. Wilhelm I, Nyúl-Tóth Á, Suciu M, Hermenean A, Krizbai IA: Heterogeneity of the blood-brain barrier. Tissue Barriers 2016, 4: e1143544

39. Keyhanian K, Umeton RP, Mohit B, Davoudi V, Hajighasemi F, Ghasemi M: SARS-CoV-2 and nervous system: from pathogenesis to clinical manifestation. J Neuroimmunol 2021, 350:e577436

40. Meinhardt J, Radke J, Dittmayer C, Franz J, Thomas C, Mothes R, et al: Olfactory transmucosal SARS-CoV-2 invasion as a port of central nervous system entry in individuals with COVID-19. Nat Neurosci 2021, 24:168-175

41. De Santis G: SARS-CoV-2: a new virus but a familiar inflammation brain pattern. Brain Behav Immun 2020, 87:95-96

42. Zwijnenburg PJ, van der Poll T, Roord JJ, van Furth AM: Chemotactic factors in cerebrospinal fluid during bacterial meningitis. Infect Immun 2006, 74:1445-1451

43. Drevets DA, Leenen PJ: Leukocyte-facilitated entry of intracellular pathogens into the central nervous system. Microbes Infect 2000, 2: 1609-1618

44. Pober JS: Endothelial activation: intracellular signaling pathways. Arthritis Res 2002, 4(Suppl 3):S109-S116

45. Li YC, Bai WZ, Hashikawa T: The neuroinvasive potential of SARSCoV2 may play a role in the respiratory failure of COVID-19 patients. J Med Virol 2020, 92:552-555

46. Zhao H, Shen D, Zhou H, Liu J, Chen S: Guillain-Barré syndrome associated with SARS-CoV-2 infection: causality or coincidence? Lancet Neurol 2020, 19:383-384

47. Yu S, Yu M: Severe acute respiratory syndrome coronavirus 2induced neurological complication. Front Cell Dev Biol 2020, 8: e605972

48. Hung EC, Chim SS, Chan PK, Tong YK, Ng EK, Chiu RW, Leung CB, Sung JJ, Tam JS, Lo YM: Detection of SARS coronavirus RNA in the cerebrospinal fluid of a patient with severe acute respiratory syndrome. Clin Chem 2003, 49:2108-2109

49. Lau KK, Yu WC, Chu CM, Lau ST, Sheng B, Yuen KY: Possible central nervous system infection by SARS coronavirus. Emerg Infect Dis 2004, 10:342-344

50. Burks JS, DeVald BL, Jankovsky LD, Gerdes JC: Two coronaviruses isolated from central nervous system tissue of two multiple sclerosis patients. Science 1980, 209:933-934

51. Pinzon RT, Wijaya VO, Buana RB, Al Jody A, Nunsio PN: Neurologic characteristics in coronavirus disease 2019 (COVID19): a systematic review and meta-analysis. Front Neurol 2020, 11: e565

52. Lechien JR, Chiesa-Estomba CM, De Siati DR, Horoi M, Le Bon SD, Rodriguez A, Dequanter D, Blecic S, El Afia F, Distinguin L, Chekkoury-Idrissi Y, Hans S, Delgado IL, Calvo-Henriquez C, Lavigne P, Falanga C, Barillari MR, Cammaroto G, Khalife M, Leich P, Souchay C, Rossi C, Journe F, Hsieh J, Edjlali M, Carlier R, Ris L, Lovato A, De Filippis C, Coppee F, Fakhry N, Ayad T, Saussez S: Olfactory and gustatory dysfunctions as a clinical presentation of mild-to-moderate forms of the coronavirus disease (COVID-19): a multicenter European study. Eur Arch Otorhinolaryngol 2020, 277:2251-2261

53. Uygun Ö, Ertaş M, Ekizoğlu E, Bolay H, Özge A, Orhan EK, Çağatay AA, Baykan B: Headache characteristics in COVID-19 pandemic-a survey study. J Headache Pain 2020, 21:1-10

54. Bolay H, Gül A, Baykan B: COVID-19 is a real headache! Headache 2020, 60:1415-1421

55. Hojyo S, Uchida M, Tanaka K, Hasebe R, Tanaka Y, Murakami M, Hirano T: How COVID-19 induces cytokine storm with high mortality. Inflamm Regen 2020, 40:e30

56. Kennedy PGE: Viral encephalitis: causes, differential diagnosis, and management. J Neurol Neurosurg Psychiatry 2004, 75:10-15

57. Moriguchi T, Harii N, Goto J, Harada D, Sugawara H, Takamino J, Ueno M, Sakata H, Kondo K, Myose N, Nakao A, Takeda M,
Haro H, Inoue O, Suzuki-Inoue K, Kubokawa K, Ogihara S, Sasaki T, Kinouchi H, Kojin H, Ito M, Onishi H, Shimizu T, Sasaki $\mathrm{Y}$, Enomoto $\mathrm{N}$, Ishihara $\mathrm{H}$, Furuya $\mathrm{S}$, Yamamoto $\mathrm{T}$, Shimada S: A first case of meningitis/encephalitis associated with SARS-coronavirus-2. Int J Infect Dis 2020, 94:55-58

58. Mondal R, Ganguly U, Deb S, Shome G, Pramanik S, Bandyopadhyay D, Lahiri D: Meningoencephalitis associated with COVID-19: a systematic review. J Neurovirol 2021, 27:12-25

59. Conte G, Avignone S, Carbonara M, Meneri M, Ortolano F, Cinnante C, Triulzi F: COVID-19-associated PRES-like encephalopathy with perivascular gadolinium enhancement. Am J Neuroradiol 2020, 41:2206-2208

60. Vaschetto R, Cena T, Sainaghi PP, Meneghetti G, Bazzano S, Vecchio D, Pirisi M, Brustia D, Barini M, Cammarota G, Castello L, Della Corte F: Cerebral nervous system vasculitis in a Covid-19 patient with pneumonia. J Clin Neurosci 2020, 79:71-73

61. Dixon L, Coughlan C, Karunaratne K, Gorgoraptis N, Varley J, Husselbee J, Mallon D, Caroll R, Jones B, Boynton C, Pritchard J, Youngstein T, Mason J, Gabriel C: Immunosuppression for intracranial vasculitis associated with SARS-CoV-2: therapeutic implications for COVID-19 cerebrovascular pathology. J Neurol Neurosurg Psychiatry 2021, 92:103-104

62. Kaneko N, Satta S, Komuro Y, Muthukrishnan SD, Kakarla V, Guo L, An J, Elahi F, Kornblum HI, Liebeskind DS, Hsiai T, Hinman JD: Flow-mediated susceptibility and molecular response of cerebral endothelia to SARS-CoV-2 infection. Stroke 2021, 52: 260-270

63. Helms J, Kremer S, Merdji H, Clere-Jehl R, Schenck M, Kummerlen C, Collange O, Boulay C, Fafi-Kremer S, Ohana M, Anheim M, Meziani F: Neurologic features in severe SARS-CoV-2 infection. N Engl J Med 2020, 382:2268-2270

64. Grau AJ, Buggle F, Becher H, Zimmermann E, Spiel M, Fent T, Maiwald M, Werle E, Zorn M, Hengel H, Hacke W: Recent bacterial and viral infection is a risk factor for cerebrovascular ischemia. Neurology 1998, 50:196-203

65. Ye M, Ren Y, Lv T: Encephalitis as a clinical manifestation of COVID-19. Brain Behav Immun 2020, 88:945-946

66. Morassi M, Bagatto D, Cobelli M, D’Agostini S, Gigli GL, Bnà C, Vogrig A: Stroke in patients with SARS-CoV-2 infection: case series. J Neurol 2020, 267:2185-2192

67. Abou-Ismail MY, Diamond A, Kapoor S, Arafah Y, Nayak L: The hypercoagulable state in COVID-19: incidence, pathophysiology, and management. Thromb Res 2020, 194:101-115

68. Varatharaj A, Thomas N, Ellul MA, Davies N, Pollak TA, Tenorio EL, Sultan M, Easton A, Breen G, Zandi M, Coles JP, Manji H, Al-Shahi Salman R, Menon DK, Nicholson TR, Benjamin LA, Carson A, Smith C, Turner MR, Solomon T, Kneen R, Pett SL, Galea I, Thomas RH, Michael BD: Neurological and neuropsychiatric complications of COVID-19 in 153 patients: a UK-wide surveillance study. Lancet Psychiatry 2020, 7 : $875-882$

69. de Erausquin GA, Snyder H, Carrillo M, Hosseini AA, Brugha TS, Seshadri Sl: The chronic neuropsychiatric sequelae of COVID-19: the need for a prospective study of viral impact on brain functioning. Alzheimer Demen 2021, 17:1056-1065

70. Daugherty AM, Chopra T, Korzeniewski SJ, Levy P: COVID-19 as a risk factor for Alzheimer's disease and related dementia: a perspective from Detroit, MI. Psychiatry Res 2020, 294:e113557

71. Raz N, Daugherty AM: Pathways to brain aging and their modifiers: Free-Radical-Induced Energetic and Neural Decline in Senescence (FRIENDS) model - a mini-review. Gerontology 2018, 64:49-57

72. Ackermann M, Verleden SE, Kuehnel M, Haverich A, Welte T, LaengerF, Vanstapel A, Werlein C, Stark H, Tzankov A, Li WW, Li VW, Mentzer SJ, Jonigk D: Pulmonary vascular endothelialitis, thrombosis, and angiogenesis in Covid-19. N Engl J Med 2020, 383:120-128

73. Verma S, Lo Y, Chapagain M, Lum S, Kumar M, Gurjav U, Luo H, Nakatsuka A, Nerurkar VR: West Nile virus infection modulates 
human brain microvascular endothelial cells tight junction proteins and cell adhesion molecules: transmigration across the in vitro bloodbrain barrier. Virology 2009, 385:425-433

74. Moses AV, Bloom FE, Pauza CD, Nelson JA: Human immunodeficiency virus infection of human brain capillary endothelial cells occurs via a $\mathrm{CD} 4 /$ galactosylceramide-independent mechanism. Proc Natl Acad Sci U S A 1993, 90:10474-10478

75. Coyne CB, Kim KS, Bergelson JM: Poliovirus entry into human brain microvascular cells requires receptor-induced activation of SHP-2. EMBO J 2007, 26:4016-4028

76. Pober JS, Sessa WC: Evolving functions of endothelial cells in inflammation. Nat Rev Immunol 2007, 7:803-815

77. Teuwen L-A, Geldhof V, Pasut A, Carmeliet P: COVID-19: the vasculature unleashed. Nat Rev Immunol 2020, 20:389-391

78. McGonagle D, O'Donnell JS, Sharif K, Emery P, Bridgewood C: Immune mechanisms of pulmonary intravascular coagulopathy in COVID-19 pneumonia. Lancet Rheumatol 2020, 2:e437-e445

79. Tian S, Hu W, Niu L, Liu H, Xu H, Xiao S-Y: Pulmonary pathology of early-phase 2019 novel coronavirus (COVID-19) pneumonia in two patients with lung cancer. J Thorac Oncol 2020, 15:700-704

80. Bois MC, Boire NA, Layman AJ, Aubry MC, Alexander MP, Roden AC, Hagen CE, Quinton RA, Larsen C, Erben Y, Majumdar R, Jenkins SM, Kipp BR, Lin PT, Maleszewski JJ: COVID-19-associated nonocclusive fibrin microthrombi in the heart. Circulation 2021, 143:230-243

81. Yamaoka-Tojo M: Endothelial glycocalyx damage as a systemic inflammatory microvascular endotheliopathy in COVID-19. Biomed J 2020, 43:399-413

82. Okada H, Yoshida S, Hara A, Ogura S, Tomita H: Vascular endothelial injury exacerbates coronavirus disease 2019: the role of endothelial glycocalyx protection. Microcirculation 2020, e12654: $1-7$

83. Droesch C, Do MH, DeSancho M, Lee E, Magro C, Harp J: Livedoid and purpuric skin eruptions associated with coagulopathy in severe COVID-19. JAMA Dermatol 2020, 156:1-3

84. Galván-Casas C, Català A, Carretero-Hernández G, RodríguezJiménez PF-ND, Rodríguez-Villa A, Navarro-Fernández I, RuizVillaverde R, Falkenhain-López D, Llamas Velasco M, García-Gavín J, Baniandrés O, González-Cruz C, Morillas-Lahuerta V, Cubiró X, Figueras-Nart I, Selda-Enriquez G, Romaní J, Fustà-Novell X, MelianOlivera A, Roncero-Riesco M, Burgos-Blasco P, Sola-Ortigosa J,
Feito-Rodriguez M, García-Doval I: Classification of the cutaneous manifestations of COVID-19: a rapid prospective nationwide consensus study in Spain with 375 cases. Br J Dermatol 2020, 183: $71-77$

85. Herold T, Jurinovic V, Arnreich C, Lipworth BJ, Hellmuth JC, von Bergwelt-Baildon M, Klein M, Weinberger T: Elevated levels of IL-6 and CRP predict the need for mechanical ventilation in COVID-19. J Allergy Clin Immunol 2020, 146:128-136

86. Perico L, Benigni A, Casiraghi F, Ng LFP, Renia L, Remuzzi G: Immunity, endothelial injury and complement-induced coagulopathy in COVID-19. Nat Rev Nephrol 2021, 17:46-64

87. Jones VG, Mills M, Suarez D, Hogan CA, Yeh D, Segal JB, Nguyen EL, Barsh GR, Maskatia S, Mathew R: COVID-19 and Kawasaki disease: novel virus and novel case. Hosp Pediatr 2020, 10: $537-540$

88. Spence DJ, de Freitas GR, Pettigrew CL, Ay H, Liebeskind DS, Kase CS, Del Brutto OH, Hankey GJ, Venketasubramanian N: Mechanisms of stroke in COVID-19. Cerebrovasc Dis 2020, 49: $451-458$

89. Tang N, Li D, Wang X, Sun Z: Abnormal coagulation parameters are associated with poor prognosis in patients with novel coronavirus pneumonia. J Thromb Haemost 2020, 18:844-847

90. Fatehi P, Hesam-Shariati N, Abouzaripour M, Fathi F, HesamShariati MB: Acute ischemic and hemorrhagic stroke and COVID-19: case series. SN Compr Clin Med 2020:1-6

91. Valderrama EV, Humbert K, Lord A, Frontera J, Yaghi S: Severe acute respiratory syndrome coronavirus 2 infection and ischemic stroke. Stroke 2020, 51:e124-e127

92. Elkhider H, Ibrahim F, Sharma R, Sheng, Sen, Jasti M, Lotia M, Kapoor N, Onteddu S, Mueed S, Allam H, Nalleballe K: COVID-19 and stroke, a case series and review of literature. Brain Behav Immun Health 2020, 9:e100172

93. Wijeratne T, Crewther S: Post-COVID 19 neurological syndrome (PCNS); a novel syndrome with challenges for the global neurology community. J Neurol Sci 2020, 419:e117179

94. Mandal S, Barnett J, Brill SE, Brown JS, Denneny EK, Hare SS, Heightman M, Hillman TE, Jacob J, Jarvis HC, Lipman MCI, Naidu SB, Nair A, Porter JC, Tomlinson GS, Hurst JR: "LongCOVID": a cross-sectional study of persisting symptoms, biomarker and imaging abnormalities following hospitalisation for COVID-19. Thorax 2021, 76:396-398 